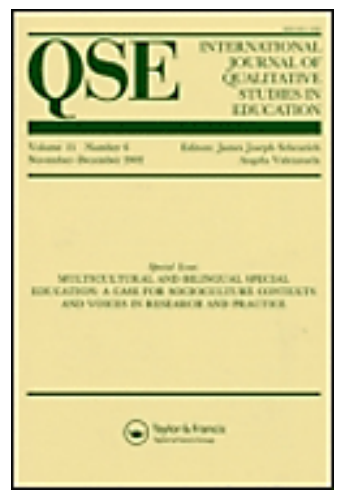

\title{
Troubling troubled school time: posthuman multiple temporalities.
}

\begin{tabular}{|r|l|}
\hline Journal: & International Journal of Qualitative Studies in Education \\
\hline Manuscript ID & Draft \\
\hline Manuscript Type: & Original Paper \\
\hline Keywords: & posthumanism, Barad, mysopedy, chronos, decolonisation \\
\hline \multicolumn{2}{|l}{} \\
\end{tabular}

\section{SCHOLARONE \\ Manuscripts}




\title{
Troubling troubled school time: posthuman multiple temporalities
}

\author{
Walter Omar Kohan \\ State University of Rio de Janeiro \\ Karin Murris \\ University of Cape Town
}

\begin{abstract}
Inspired by the philosophies of Donna Haraway and Karen Barad, the aim of this paper is to stir up trouble and to trouble school time. What we intend to disturb puts our own self as human at stake through a philosophical investigation in how a particular relationship to and experience of time is nowadays prominently fostered and cultivated in educational institutions. We propose that 'time' and 'childhood' are intrinsically entangled concepts and logically connected, in the lived experience of educational contemporary institutions, with colonialism and capitalism. Decolonisation requires a troubling of the experience of time as it involves the subordination and denigration of children and childhood ('mysopedy'). We do this through a genealogy (a political reading of 'the' present) of the concepts time, childhood and school.
\end{abstract}

Keywords: Barad, posthumanism, chronos, mysopedy, childhood, decolonisation

\section{Troubling troubled school time}

In these troubling times, the urgency to trouble time, to shake it to its core, and to inspire collective imaginaries that undo pervasive conceptions of temporality that take progress as inevitable and the past as something that has passed and is no longer with us, is something so tangible, so visceral, that it can be felt in our individual and collective bodies (Barad, 2018, p.206)

As Donna Haraway reminds us, 'trouble' is a significant word, coming from a French verb meaning "to stir up", "to make cloudy", "to disturb" (Haraway, 2016, p.1). In the 
already troubled, disturbed and cloudy educational times we live in, the aim of this paper is to stir up more trouble and to add to the disturbance. Geologists claim that 'our' time is that of the Anthropocene, a human-damaged planet (Crutzen and Stoermer, 2000). Through the standardisation of global time, the mechanisation of labour and the extraction of fossil fuels, industrial capitalism has put 'the human' on a linear time line of progress. Advanced capitalism and colonialism have turned education into an individualised, teleological humanising project, whereby human and other beings have become a resource, obscuring collaborative survival (Snaza, 2015, pp.26-27; Tsing, 2015, p.19). Our ability as humans to 'look forward' has become entangled with what it means to be human: a superior species with 'agency', 'consciousness' and 'intentionality' - setting us ontologically apart from and above nonhumans in the order of things (Tsing, 2015, p.21). For Haraway, the solution does not lie in trying to make an imagined future safe, but to stay with the trouble by "learning to be truly present" (Haraway, 2016, p.1). This requires, Anna Tsing (2015, pp.17-25) suggests, "the arts of noticing": a noticing of entanglements of bodies with bodies, and time with other times (Swanson, Tsing, Bubandt and Gan, 2017, p.M7). This noticing as a kind of multispecies ethnography that includes the nonhuman requires a different kind of writing that draws on more than description and rational argumentation and includes storied accounts, the imagination, and rich descriptions of what is present and not present (at the same time) by tracing multiple temporalities (Barad, 2018; Tsing, 2015). It also requires from the reader an openness to be affected by a kind of writing that disrupts, disturbs and troubles the usual logical flow of academic unilinear writing where one argument follows another.

Through experimental multilinear writing, we put our own self as human at stake and investigate philosophically how a particular relationship to and experience of time is fostered and cultivated in educational institutions, that is, schools, in the broader sense of the word. What this article contributes to, is a non-western perspective on time in education through an ontological reconfiguration of subjectivity. As Riyad A. Shahjahan $(2018$, p.10) in his review of four recent books on time in higher education points out, western scholarship is limited in that it ignores that humans "are also governed by physical and biological cycles that go beyond human agency" and do not question the coloniality of power of western theorisations of temporality. Apart from disrupting the anthropocentrism and human exceptionalism 
characteristic of western humanism, we also propose that 'time' and 'childhood' are intrinsically entangled concepts and logically connected, in the lived experience of educational contemporary institutions, with colonialism and capitalism. The internal structure of the childhood of both individuals and society as inferior, is a particular colonising notion of time.

Decolonisation requires a troubling of the experience of time in contemporary school as it involves the subordination and denigration of children and childhood. We do this through a genealogy (a political reading of 'the' present) of the concepts time, childhood and school. We adopt Kyoko Hayashi's idea of "travel hopping” (Barad, 2018, p.222) and re-turn to 'historical' accounts of childhood and childhood memories, but not in a psychological sense. Memory is not owned by a self as a property of individual subjects, but a material condition and "written into the flesh of the world" (Barad, 2017a, p.49). The past is not simply given and the act of remembering is not a subjective activity of the human mind. Memory is not a linear record of a fixed past that can be ever fully or simply erased, written over, or recovered, as if past moments were like beads on a string, but we re-member childhoods as an embodied reconfiguring of past and future that is larger than any individual (Barad, 2007, p.ix; 2007, p.394; 2014, p.168; 2018, p.239). The method of 'travel hopping', or temporal diffraction, is a transindividual commitment to undo the injustices committed to those who are (also) no longer there (as well as our 'own' childhood 'selves'), without any pretense that the past can be made undone as in the notion of time travel (Barad, 2018, p.222). Events 'in' 'the' past are neither singular, nor locatable and leave traces (Barad, 2017a, p.63), and the "world 'holds' the memory of all traces" (Barad, 2017a, p.48). Travel hopping as an art of noticing multiple temporalities is not like writing a linear chronological history, but a tracing of the specific material-discursive entanglements that matter in terms of the politics of time and childhood. As Tsing (2015, p.21) puts is poignantly:

Progress is a forward march, drawing others kinds of time into its rhythms. Without that driving beat, we might notice other temporal patterns.

\section{School, misopedy and colonialism}


School, etymologically comes from the Greek schole, meaning 'leisure', 'rest', 'ease' (Liddell \& Scott, 1966), but mainly for privileged adults, and was ironically in part established in Ancient Greece and Modern Europe through child labour and slavery ${ }^{1}$ (Rollo, 2018, p.64). The ancient conception of the degraded, not fully human, child "misopedy"2 - is the internal logic that has made colonial superiority (the colonial denial of full humanity) and the notion of the ontological 'other' possible (Rollo, 2018, p.61). Rollo (2018, p.61) explains:

The idea of a telos of progress from animal child to human adult is both a historical and conceptual antecedent of the idea of European civilization, prefiguring its stories about maturation and progress from cultural ignorance to enlightenment.

A specific understanding of childhood has made it possible to conceptualise all 'notfully-humans' as ignorant, immature, uncivilized animals by Nature (Murris, 2016) and therefore they need faith (premodernity) and reason (modernity) in order to progress and develop into fully-human beings (Rollo, 2018, p.63). This means that age is not just another category of exclusion, like race, gender or class, but "the degraded figure of the child provides the internal structure and logic of the colonial conception..." (Rollo, 2018, p.63; our italics) of the deficient 'other'. The comparison between the colonising of ('developing') nations, women, people of colour and people living in poverty is, therefore, not just a paternalistic analogy, but a homology - a sharing of essential structures: these subhumans are children (Rollo, 2018, p.63). Misopedy is not only about children, that is, young people of a particular age, but includes "all feral children of civilization, including white European ancestors" (Rollo, 2018, p.61). Key to this internal structure of the childhood of society as inferior is a particular notion of time. In other words, while a specific concept of childhood is at the base of a colonizing civilization, the concept of time as linear, chronos, is operating not only in ancient misopedy but also in modern colonialism as well. As such, chronos, childhood and school are an entangled phenomenon. In modern times, when

\footnotetext{
${ }^{1}$ The Greek word 'pais' is the same word for both child and slave and was used both for girls and boys (Golden, 1990: 15).

${ }^{2}$ Canadian scholar Toby Rollo prefers the term "misopedy" over 'childism', because the latter is also used to deny childhood dignity. Misopedy denotes "a non-clinical sense of antipathy towards children and childhood". As opposed to the clinical term 'misopedia' introduced by psychologists in the $19^{\text {th }}$ Century (Rollo, 2018: 16ftn 2).
} 
school became a place to form children into the civilized adults of the Enlightened society, school was turned into a chronological institution ${ }^{3}$.

A few examples on the historical semantic change of some words might help us to see more clearly what is at stake. In Ancient Greek there are a few words that mean child (paîs, neós, tekno), each one having a different semantic connotation. Significantly, there is no word for childhood. Plato for example, invented lots of words and dedicated quite a significant space in dialogues such as The Republic and The Laws to discuss the education of childhood. But for some unknown reason, he did not create a word for childhood. In modern Greek, though, there is a word for childhood: paidiké elikia, which literally means 'aged as a child', that is, childhood is linguistically associated to being a chronological child through a chronological category such as age. We will discuss time further in the next section of this article, the ancient Greeks had other words than chronos: kairos and aion. In Heraclitus (fr. 52), aion is identified with a child childing, the kingdom of a child. In Plato's Timaeus (37d), aion has the meaning of eternity and chronos is defined as the numbered image of aion. But in modern Greek, aion means "century", a specific chronological time. Hence, for a modern Greek it is not easy to think childhood and time out of chronos. Similarly, schole has completely lost its original meaning of 'free-time' and now simply means the institution of school.

These discursive shifts illustrate how the chronological status of school, since Modernity, is a place where time is experienced in the form of a linearity of successive, consecutive and irreversible movements creating a dividing line between past and future; the present being just a limit of both of them but in fact having no 'substance'. If school time is mainly chronological time, then it is composed of past and future. In school there are no opportunities to experience a present time; put more strongly, the present does not literally exist in schools other than as a limit, border or edge between past and future. What counts in school are past experiences - and, in particular, past experiences of schooling (reports, tests, previous learning) - and

\footnotetext{
${ }^{3}$ In our times, schools are regulated and organized by chronos. Students are divided, grouped and classified on the basis of age; curricula are chronos based (classes of $\mathrm{x}$ minutes, disciplines and credits of $x$ number of hours, semesters, years, etc); and the whole educational system is chronologicaly organized (pre-school from $\mathrm{x}$ to $\mathrm{x}$ years old; elementary school, $\mathrm{x}$ number of years; high school, $\mathrm{y}$ number of years, etc.). We develop this argument further below.
} 
always with a focus on the future; a time of being made 'ready' or 'prepared' for the next school year, phase, stage, university, or even the labour market. With this logic of linear progression, school has been positioned at the heart of a civilization process (Culture) in aid of developing the wild and ignorant (Nature) to become 'fully-human', whether as individuals or as species (developmentalism) (Murris, 2016). The concept of childhood has shaped how we relate to time at school and vice versa. Through the learning of such a naturalised conception of time, school forms the kind of regulated subjects that know when and how to desire what the capitalist society cultivates them to desire.

We are aware that the question of time is one of the major questions in Western philosophy and a comprehensive overview is neither possible, not is it the objective of this article. Within the word limits, our aim is, to start from a classic and influential definition of time as chronos (which is human centered and assumes human exceptionalism) to trouble school time.

The troubling of this troubled school time is not an easy endeavour. Since the Enlightenment, so-called inferiority in reasoned $\operatorname{speech}^{4}(\operatorname{logos})$, through which the intellect is evaluated and assessed, is not seen as innate and inherent in the subhuman, but understood as temporary and should be 'fixed' through schooling (Rollo, 2018, p.70). The associated moral superiority of the adult colonizer explains the resilience of misopedy and its intricately related use of time (linear progress) in school. The adult as saviour is seen as in a hierarchical and authoritative position to cultivate the inferior non-civilised 'other' - even as a means to justify the use of violence (Rollo, 2018, p.63). It is this moral superiority that is disturbing as misopedy is sedimented in school as chronological institution. We stir up trouble by troubling chronological time and with it chip away at sedimented misopedy.

In other words, this article is an attempt to double trouble time in education. We trouble how certain views of childhood shape our experience of school time and secondly, we trouble the way in which time as experienced in school, affects how

\footnotetext{
${ }^{4}$ Rollo (2018, p.65) points out "how the terms baby, babble, and barbarian derive from the same IndoEuropean root baba, connoting the incomprehensible speech of the infant (likewise, 'infant' from the Latin in fans, connoting 'without speech')".
} 


\section{Quantum Field Theory, Niels Bohr and Karen Barad}

Barad argues that the findings of Quantum Field Theory $(\mathrm{QFT})^{8}$ have radically changed our understanding of the nature of space, time and matter, in that its indeterminacy principle 9 "troubles the scalar distinction between the world of subatomic particles and that of colonialism, war, nuclear physics research, and environmental destruction". She asks: "In these troubling times, how can we not trouble time?" (Barad, 2018, p.215). QFT combines quantum physics, relativity and field theory (Barad, 2017a, p.53). So in

\footnotetext{
${ }^{5} \mathrm{We}$ are not going to enter in the specificity of the actual presence of (digital) technologies in school. Our assumption is that a chronological (linear, binary) concept of time is still operating in them.

${ }^{6}$ Why this is curious is that posthumanists (although Haraway [2016] distances herself from the term) assume a radical kind of equality and egalitarianism. They do not focus on (humanist) identity (black, female, rich, working-class), nor even multiple identities, but break with anthropocentrism altogether. For example, Karen Barad (2007, 2012, 2014) celebrates differences produced in material-discursive relationships, differences that exclude or include; in other words, differences that matter.

7 Through a "cutting-together-apart" (Barad, 2014): from-child-within-adult-within-child. Each position in spacetime is a multiplicity - a superposition.

${ }^{8}$ Quantum Field Theory (QFT) combines "quantum physics, special relativity and classical field theory" (Barad, 2018, p.218).

${ }^{9}$ Officially called: "the position-momentum indeterminacy principle" (Barad, 2018, p.218)
} 
what way does QFT trouble time and what is Barad's contribution to our understanding of time in its relationship to childhood and school?

Deeply influenced by both feminist theorist Donna Haraway and quantum physicist Niels Bohr, Karen Barad's significant contribution to both physics and philosophy is to see the ontological implications of what Haraway and Bohr before her thought were mainly epistemological issues. Bohr's famous two-slit diffraction experiment ${ }^{10}$ (Barad, 2007, p.81-84) made evident that under certain conditions light behaves like a particle (as Newton thought) and under other conditions it behaves like a wave, described by Bohr's influential complementarity theory. Electrons are neither particles nor waves - "a queer ${ }^{11}$ experimental finding” (Barad, 2014, p.173). Wave and particle are not inherent attributes of objects. But, "the nature of the observed phenomenon changes with corresponding changes in the apparatus" that measures it (Barad, 2007, p.106). Electrons and the differences 'between' them are neither here nor there, this or that, one or the other or any other binary type of difference; and what holds for an electron also holds for a human animal (Barad, 2014, p.174-175). Although it might seem counter-intuitive to extrapolate findings from 'micro'-level to 'macro'-level, an agential realist reading of QFT explodes the temporality of the modernist conception of science - embraced as the epitome of progress as well as its ideal (Barad, 2017a, p.26). Quantum entanglements are at the heart of Barad's relational agential ontology. It is not about the interconnectedness of all beings, but agential realism offers an analytical frame for asking questions about how space, time and entities come into being in their materiality (Barad, 2017b, p.G111).

Like Bohr, Barad's holds the position that the primary ontological units are not independently existing objects with independently determinate boundaries and properties (as in realism and time according to Newton), but phenomena that are not located in space and time - material entanglements that are the "basic units of reality" and "not mere laboratory creations" (Barad, 2007, p.33). This meta/physical shift from things to phenomena facilitates a radically different understanding of time, as neither objective, nor subjective, but time is mutually constituted through entangled agencies (incl. technology,

\footnotetext{
${ }^{10}$ For a helpful basic explanation of the experiment: https://www.youtube.com/watch?v=Iuv6hY6zsd0

${ }^{11}$ As we have seen earlier, with 'queer' Barad does not just mean 'strange' but it disrupts the Nature/Culture binary and is therefore an 'undoing of identity', because waves and particles are ontologically different entities. It raises the key question how is it possible that an electron can be both? See: https://www.youtube.com/watch?v=cS7szDFwXyg. [Accessed: 21/02/2015].
} 
such as computers, phones and the internet). These agencies do not exist as individual elements, and are "only distinct in relation to their mutual entanglement" (Barad, 2007, p.33). In other words, time does not unfold as "linear forward motion" (Barad, 2017a, p.49), but the ontology of entities emerges through their relationality, and not only at quantum level. Barad argues that scale is not simply a given, but human-made:
When the splitting of an atom, indeed, its tiny nucleus, destroys cities and remakes the geopolitical field on a global scale, how can anything like an ontological commitment to a line in the sand between "micro" and "macro" continue to hold sway on our political imaginaries?” (Barad, 2018, pp.213-214).

Quantum physics gives experimental evidence that subject and object are inseparable non-dualistic wholes, and this includes humans (Barad 2007). Importantly, Barad's interpretation of quantum physics relies on the empirical ${ }^{12}$ facts that show that there is direct, not mediated (e.g. through language or measurement) epistemological access to 'the' world. Knowledge is constructed through "direct material engagement with the world" and not by "standing at a distance and representing" the world (Barad, 2007, p.49). One must perform in order to see: "you learn to see through a microscope by doing not seeing" (Barad, 2007, p.51). Similarly, the knowledge created in this article is performative. The intention is not to represent existing literature, or to offer a literature review but to experiment with short bodies of texts, also in their materiality.

The recently published text from Barad (2018) we will be diffracting through is about the troubling of both Newtonian physics and the idea of 'empty' time, which she equates with universalising, totalising political projects such as imperialism and capitalism. We have adopted this text because of the different conception of time as not empty she argues for, thereby opening up decolonising possibilities to include "indigenous and other subjugated knowledge practices" (Barad, 2018, p.212). The text itself is a diffractive reading of Kyoko Hayashi's From Trinity to Trinity (2010). Although feminist posthumanists do not refer to misopedy, neither engage with children's structural and institutionalised discrimination, nor regard children's

\footnotetext{
${ }^{12}$ In personal conversation, Karen Barad has explained that 'empirical' is only used here to highlight the fact that the claim made is about the real world, but of course her agential realism disrupts the binary this use of language implies.
} 
knowledges or being in the world as falling under subjugated knowledges, her moving text affects us at a deep level, creating possibilities to open up fresh philosophical enquiries into the ethics and politics of time in school. To use diffraction - a materialist methodology that also troubles unitary and chronological conceptions of space and time - is an obvious choice.

\section{Temporal diffraction - also as methodology}

Diffraction is a postqualitative methodology developed, first by Donna Haraway (1988), and built on by Karen Barad through her diffractive reading of quantum physics $(2003,2007,2012,2014,2018)$, but importantly should not be understood as a metaphor, which would imply representationalism. Diffraction as a methodology is different from reflection (Bozalek \& Zembylas, 2017). Diffraction means "to break apart in different directions" (Barad, 2014, p.168). Diffraction patterns hold for water waves, as well as sound waves, or light waves (Barad, 2007, p.74). It is where they interfere or overlap that the waves change in themselves in intra-action and create a "superposition" (Barad, 2007, p.76). Unlike the notion of diffraction in classical physics that compares 'this' with 'that' as in an analogy, Barad explains that her notion of diffraction (referring to Trinh Minh-ha) is "allied with the fundamental quantum physics notions of superposition and entanglement, where difference is a matter of differences within, not the 'apartheid type of difference'"13 (Barad, 2018, p.216). She explains that:

To be in a state of superposition between two positions, for example, is not to be here or there, or even here and there: rather, it is to be indeterminately herethere - that is, there is no fact of the matter (it is not simply that it is unknown) as to whether it is here or there" (Barad, 2018, p.216)

\footnotetext{
${ }^{13}$ When reading Karen Barad re-turned to this text by reading it aloud at a seminar in Cape Town, June 2017, some delegates pointed out their discomfort with Trinh Minh-ha use of 'apartheid' (see also Barad, 2014), as its abstract use here does not to justice to the painful and violent context of human suffering in South Africa.
} 
This does not mean that a particle can be at two places at once, but that the path of a particle from one position to another is indeterminate and the sum of all parts is a superposition (Barad, 2018, p.218-219).

Much less well known in the field or used in posthumanist research is temporal diffraction. Based on another indeterminacy principle ${ }^{14}$, the significance of this principle ontologically is that, according to $\operatorname{Barad}$ (2018, pp. 219-220):

... a given entity can be in (a state of) superposition of different times. This means that a given particle can be in a state of coexisting at multiple times - for example, yesterday, today, tomorrow. However, temporality is not merely multiple, rather, temporalities are specifically entangled and threaded through one another such that there is no determinate answer to the question "What is time"? There is no determinate time, only a specific temporal indeterminacy. The diffraction pattern, in this case, is a manifestation of different times bleeding through one another.

In other words, any entity (micro 'and' macro) can "co-exist in a superposition of multiple places and times" and all possible histories need to be taken into account (Barad, 2018, p.220). Linear histories ${ }^{15}$ co-exist with and through one another.

Although common, this is not always evident (Barad, 2018, p.217). In other words, Barad does not reject chronological time, but radically reworks it from within through diffraction as methodology: different times are "bleeding through one another" (for an example of making temporal diffraction visual, see: Murris \& Babamia, 2018, p.169).

So how does the diffractive methodology work? Rather than looking for similarities or making comparisons between, for example, philosophical texts, reading one against the other or pointing out what each might lack, the method is affirmative, creative,

\footnotetext{
${ }^{14}$ This important principle in QFT is officially called "the time-energy indeterminacy principle" (Barad, 2018, p.220)

${ }^{15} \operatorname{Barad}(2018$, p.220) explains: Linear combinations of (different) times, not moments or events sequenced in time.
} 
connecting, nonrepresentational and ethical (Murris\& Bozalek, 2019). By paying attention to the differences that matter without creating oppositions, new patterns of thought, interference patterns and 'superpositions' are created - a 'cutting togetherapart' as one move (Barad, 2014). Diffractively reading bodies of texts through one another breaks with the temporality of progress. Barad (2017a, p.37) explains the methodology as follows:

The material fragments are neither to be read as causally linked (in the sense of linear causality) nor merely analogous. Rather, they are to be picked up like crystals, and turned around and around allowing the light to diffract through them, seeing the overall pattern that is already inside each fragment but also watching entire constellations of insights flash up, if only momentarily.

This new feminist academic style honours our inheritances, because diffraction patterns are always already there, that is, the point is "to make evident the always already entanglement of specific ideas in their materiality" and to explore patterns of difference in ethical ways that trouble binaries that support analogical analysis, such as nature/culture, macro/micro, etc. (Barad, 2018, p.216). Hence, the diffractive apparatus is not about making analogies, or pulling together ideas in Deleuzian assemblages, but tracing some entanglements by focusing on the specificities of texts and ideas and what might not be visible, there and then. The methodology troubles linear writing and research practices, 'first here, then there', 'first this, then that'. It involves dis/continuity in the form of writing - a break in the flow (Barad, 2017a, p.38). 'Travel hopping' is not like writing a linear chronological history, but a tracing of specific material-discursive entanglements. In this case, the concepts that matter in terms of the politics of time and childhood, although of course some kind of linearity is inevitable when using the technology of writing.

Travel hopping disrupts the idea of doing research by first defining this concept and then that concept - a chronological use of time, so dominant, in writing as well as in schooling. In contrast, in the remainder of the paper, we read diffractively through one another, Barad's philosophy of chronological time and other notions of time from Western academic philosophy and aim to do justice to "multiple temporalities" (Barad, 
2018, p.221). Our re-turning to experiences of living and working with young children are always already diffractively threaded through the analysis, although not always visible (times are 'bleeding through one another').

Such a non-representational way of doing research considers "the entanglement of bodies, texts, relationships, data, language, and theory...[with] the possibility of much productive potential" (Mazzei, 2014, p.745). What follows from this is that different ways of understanding time are diffractively already threaded through one another, so the idea is not to 'progress' to a 'better' understanding of time, replacing one with the other (Barad, 2018, p.221). As opposed to many physicists, Barad (2018, p.224) claims that the well-known 'quantum eraser experiment' does not show that the past can be changed, but that the ontology of an entity "in the past remains open to future reworkings". The past is not 'closed' or 'finished', "'[N]ow' is shot through with 'then"” and crucially, any attempts of erasure (a material practice) leaves traces in "the very worlding of the world...the world holds its memories of its iterative reconfigurings" (Barad, 2018, p.226). The task for the researcher is to trace the entanglements whilst she herself exists in multiple temporalities and without bodily boundaries (Barad, 2007).

\section{Queering individualism and identity}

Barad's diffractive reading of queer theory and quantum unsettles modernity's unified notions of the self and a metaphysics of presence with its disentangling of epistemology, ontology and ethics that has led to unspeakable cruelty to the subhuman (e.g. child, woman, black people) and the nonhuman. Her agential realism (Barad, 2007, 2012, 2014) implies that "the past remains open for future re-workings" and yet, the traces of iterative materializations are "sedimented into the world" as "the world holds the memories of its iterative reconfigurings" (Barad, 2018, p.226), hence a response-able diffractive reading is in that sense objective. But also, as authors we make these diffractions, or intra-actions, work in a particular way, without positioning ourselves outside of it. The diffractive method calls into question the individual/group binary and problematises the nature of identity and individual existence. In other words, posthuman philosophy brings forth its own posthuman method of analysis: 
diffraction queers binaries such as subject/object, cognition/emotion, researcher/world, child/adult, aion/chronos. Our diffractive analysis moves in in/determinate multidirections, including unpredictable causal factors, and opening up a space for human and more-than-human bodies to also produce affect and intensities, thereby keeping analysis and knowledge production on the move.

Unlike a literature review, in our diffractive reading we have interspersed in a different font, our own entangled re-memberings of aionic ${ }^{16}$ child experiences of time diffracted through chosen citations from Barad's text Troubling Time/s and Ecologies of Nothingness: Re-turning, Re-membering, and Facing the Incalculable (2018). The aim is to affect the reader and to think differently about the theory and practice of time in school for a "justice-to-come" (p. 213). The past can be re-worked but not erased. We have seen how travel hopping is dis/embodied material-discursive labour involving a re-working of the past, not by creating a unilinear chronology, but an un/doing of universal time - the idea that moments exist one at a time, the same everywhere, replacing one for the other. It also disrupts what it means to be a human (or a collective of humans) 'with' memories - moving as a fleshy unit 'in' space and 'through' time (the modernist notion of the self with, for example, individual agency and rights). Instead, living as porous human bodies without bodily boundaries implies that it is impossible to write 'a' history (e.g., of philosophies of time or an autobiography) objectively in the traditional sense as this would involve powerproducing dualisms between self and world. The past is never 'here' or 'there' in the sense of objectively fixed, determined and static. However, it does not follow that the past is not real. It reminds us of Brian Massumi's doubling quality of affect: "The experience of a change, an affecting-being affected, is redoubled by an experience of the experience" (Massumi 2015, p.4). Re-turning to experiences is an entering of a past that was never there for the 'taking' and intensifies the affect that experiencing the experience has on human and nonhuman bodies. Hence, we continue in this article with the em/bodied practice of reading diffractively through one another rememberings of childhoods, Barad's text on temporal diffraction (2018) and different philosophies of time. Their material positioning in the text are carefully framed to create diffraction patterns. To reiterate, this kind of writing involves the arts of

\footnotetext{
16 See below for an explanation of aion.
} 
noticing as a kind of ethnography that draws on more than rational argumentation and includes storied accounts, the imagination, and rich descriptions of what is present and not present (at the same time) by tracing multiple temporalities (Barad, 2018; Tsing, 2015). It deliberately breaks the flow of reading and creates interference or diffraction patterns that are political in that they queer identity-creating binaries (e.g., reader/writer; adult/child; objective/subjective; critical/creative). It also helps us think differently about childhood's multiple temporalities but requires a particular effort of the reader to notice and be affected by other temporal patterns that trouble the pervasisve rhythm of progress in schooling.

\section{Diffracting chronos, the multiplicity of school time, re-memberings of childhoods}

As we anticipated, Plato defines chronos as "the moving image of eternity (aion) that moves according to number" (Timeus, 37d). For the Athenian, there are two kinds of time, the time of the perfect and most real beings, the Forms, which are aionic, eternal, not submitted to generation and destruction; and the time of the imperfect world of matter, of becoming in which we live. The latter is an image of the former, being the time of 'our world', chronos an image of time of the 'perfect world', aion, conceived as eternity. Plato's influential disciple, Aristotle, did not accept his master's distinction, and defined chronos by itself, without images, as "the number of movement according to the 'before and after'" (Physics IV, 220a). According to this definition, chronos is a line of "before-after" movements, being the past the movements already happened and the future the movements expected to happen. If time is the numbered measure of movements, then present has no materiality other than the 'now', a limit or frontier between past and future. ${ }^{17}$

The time of chronos can be represented as a line of successive, consecutive and irreversible moments. This Ancient Greek conception of time has had an enormous productivity in Modern and Contemporary times.

\section{Clock time is what Walter Benjamin poignantly calls "homogenous empty time." Whether calibrated to a projected future, an}

\footnotetext{
${ }^{17}$ For a more detailed account, see Kohan, 2016.
} 


\title{
individual event, or a periodically recurring phenomenon, time is tuned to a succession of discrete moments, where a moment is understood to be the thinnest slice of time, and where each successive moment replaces the one before it. ${ }^{18}$
}

\begin{abstract}
One realm where this time has been especially productive is in institutionalised education (see also, for example, Pacini-Ketchabaw, 2012). It is the unilinear, chronological version of time that underpins educational public policies and norms, and is presupposed in the organization of pedagogical work in schools.
\end{abstract}

Liam did his maths test today and tells me he run out of time. I remember wondering: how can you run out of time for a test? Surely, you know it or you don't? Why does it matter how long he takes over it?

In order to get to $5^{\text {th }}$ grade we have to first pass $1^{\text {st }}$ to $4^{\text {th }}$ grades, and in that precise order. You cannot start $2^{\text {nd }}$ grade until $1^{\text {st }}$ grade is completed. Similarly, you cannot begin with the contents of the third unit of a curricular program before the second unit is completed. Mathematics in $6^{\text {th }}$ grade comes after Mathematics in $5^{\text {th }}$ grade. This linearity of time is also the dominant time of school experience; there is no way to institutionally live the second hour of the day before finishing the first. You can only go to the break until the entire hour scheduled before has passed. You cannot arrive to start the second semester before the first has passed. And once a given time has passed there is, apparently, no way to experience it again. If we don't pass an exam we can repeat it, but we cannot go back to the past, undo it and redo it. Content knowledge is carefully organised and concepts are taught one at a time. First this, then that.

Inspired by Barad's agential realism, Veronica Pacini-Ketchabaw (2012, p.157) argues that the clock as a material-discursive apparatus is entangled with the way bodies are produced, disciplined and colonised and "produces particular knowledges about what it means to be an educator and what it means to be a child in an early childhood classrooms" (Pacini-Ketchabaw, 2012, p.155). The clock, children and educators e/merge as processes through the use of time in schools (Pacini-Ketchabaw, 2012, p.158)

\footnotetext{
${ }^{18}$ Barad, 2018, p. 210.
} 
The analog clock that the educator wears on her wrist affords the waiting body of a child, as Sophia watches the clocks hands reposition. Hers is not merely a body that exists, but a body that waits ${ }^{19}$.

This notion of time seems to be rather intuitive in the so called west, probably because it is also the socially dominant time in most of our societies. At school, we not only learn to experience a given time but a relationship to time. We learn to be projected in a future to come. We learn the anxiety of the expectation of that future to come.

I am 4. Algiers. It is 5 December and hot. It is Sinterklaas and I am sitting on his lap in kindergarten. His servant, Zwarte Piet, stands next to him with his bag full of goodies. The bag is also used to put naughty children in - the ones like me who have been sucking their thumbs. My mum warned me the whole year. I am terrified. Then I look at Zwarte Piet. His face is painted black, but I recognize the smile and his front tooth is broken. It is my dad.

Time is nationalized, racialized, out-of-joint 20 .

We all expect the winter to finish so spring can emerge, we look forward to becoming 18 years old, no longer minors, or to celebrate our birthdays in order to receive congratulations and presents. And once that has happened we will have to wait one whole year, three hundred and sixty-five movements of one day, or eight thousand seven hundred and sixty movements of one hour, no less no more, to experience another birthday. In this time learned, presents go away as fast as the present. This chronological time ${ }^{21}$ seems to be a neutral, objective and universal representation of time. Not so, according the QFT (as we have seen above).

\footnotetext{
${ }^{19}$ Pacini-Ketchabaw, 2012, p.158

${ }^{20}$ Barad, 2018, p.227.

21 The problem is not necessarily that time is understood as linear. Cyclical time, for example, associated with 'natural' cycles and feminism, is also linear. The concern in childhood studies is with the claimed universality, objectivity, causal sequencing, irreversibility and quantitative measurability of chronological temporality. See, e.g., Honkanen, K. (2007). 'Aion, Kronos and Kairos: On Judith Butler's Temporality'. Journal of Queer Studies in Finland. Available on: https://journal.fi/sqs/article/view/53674/16796; Accessed 04/08/2018. As Karen Barad (2018, p.220) argues: Diffraction patterns are based on linearity: "not a linearity of moments or events evenly distributed in time, but a linear combination of (different) times". Each history, Barad argues, "coexists with the others" (p.220).
} 


\section{...(even) linearity is susceptible to radical workings from within ${ }^{22}$}

There is not on the one side, the past there, already defined, immobile and completely accomplished, and on the other side, the future not already existing, waiting in order to be for the present to open the door of the time movement so that the future can enter the realm of being. On the contrary, both past and future are part of the mutually intraactive world of phenomena, one affecting the other, both iteratively reconfirmed and reformed through each other and with the present: the past never being a complete 'already-past' and the future never being yet not already being, the present never being just a limit or division between two uncontaminated parts. What happens when, being a (non chronological) child we re-turn to our own (chronological) childhood? What was it like be(com)ing a (non-chronological) child?

\section{... a given entity can be in (a state of) superposition of different times. This means that a given particle can be in a state of coexisting at multiple times - for example, yesterday, today, tomorrow...times bleeding through one another. ${ }^{23}$}

I am surfing the waves. Muizenberg 2017. I feel, smell the sea. South of France 1963, 1965, 1966, 1968, 1969, 1970...I see my dad, making a fort out of sand. I join him. We are silent. I only hear the sea and the sounds of our hands pushing the sand into the right place.

Time cannot be considered any longer as chronological in the sense of being a line of consecutive, irreversible and uncontaminated sequence of discrete movements, moving according to the numbering of 'before' and 'after' relationships. In spite of this ontoepistemological insight, unilinear chronological time continues to govern our world and lives.

This is the time of capitalism, colonialism, and militarism ${ }^{24}$.

It is break time. We are playing a game in the sand. With a knife we are

\footnotetext{
${ }^{22}$ Barad, 2018, p.220

${ }^{23}$ Barad, 2018, p.220.

${ }^{24}$ Barad, 2018.
} 
carving up the space into territories. Who throws best has the most land. I laugh. The school bell rings.

Chronological time constitutes a hegemonic system of domination (Barad, 2018) in service of the forms of discipline (Foucault, 1995), control (Deleuze, 1990), and biopower (Hardt \& Negri, 2001) that regulate bodies in institutions like school.

\section{School as schole, kairos and aion}

The Greek word from where all the words for school in Romance Languages come from is the already mentioned schole. In Latin, schole was translated as otium, from where neg-otium, the negation of otium, the anti-school emerges. ${ }^{25}$ According to Jacques Rancière, school is born, as schole, as an eminent space of equality. It establishes a division between those who are inside schole equally experience freetime, opposed to those who, outside schole, experience time under the logic of production and need to justify in terms of its productivity their uses of time. That is why school is not born specifically as a space to learn (because we do not need a school to learn) but of experiencing time in a way we cannot experience outside school (Rancière, 1988). Inside schole, regardless its social class, history, culture each student equally experience time freely, for the sake of itself, liberated from the constraints and determinations of the dominant social values. ${ }^{26}$

Before continuing our analysis of school time it might be helpful to recall two other notions of time present in Ancient Greek. Another word for time is kairos, literally 'measure', 'proportion' and, in relation to time, 'critical time', 'season', 'opportunity' (Liddell \& Scott, 1966, p.859). In chronos every "moment" is qualitatively the same as any other moment. Differently, in kairos a moment is never equal to any other moment in the qualitative sense. The same action that brings death one moment, might bring life, if done only a few seconds later. Kairos is, therefore, more responsive to

\footnotetext{
${ }^{25}$ In the Latin American tradition, Simón Rodríguez (2001), philosopher and educator of the nineteenth century, problematised the relation of otium (leisure time) and school by strongly criticizing the colonisation of school time by those who seek to reduce school to the site of a negotium, in Spanish negocio, the negation of otium. Those who take school for granted, then, are involved in anti-schooling. For a contextualisation of Rodriguez' ideas regarding schole, see Author 2, 2015.

${ }^{26}$ Based on this insight, Belgians pedagogues, Jan Masschelein and Maarten Simmons have unfolded a sophisticated analysis of school as a form. See their In defense of school, 2014.
} 
diffraction as method than chronos. In contemporary scholarship, kairos is considered the time of the hermeneutical experience of education (Wiercinski, 2017).

Can we do that later, Milena? No, dad, it has to be now.

A third Greek word for time is aion, that designates from its most ancient occurrences in Homer, the intensity of time in human life, a destiny, a duration, an un-numbered, qualitative state (Liddell \& Scott, 1966, p.45). In one famous and endlessly interpreted fragment of Heraclitus (DK 22 B 52), aion appears in connection to childhood: the fragment literally says that: "aion is a child playing [literally, "childing"] ${ }^{27}$, its realm is one of a child, childlike". The fragment affirms a strong connection between aionic time and childhood. As if the experience of a child passes in aionic and not chronological time, or, in other words, as if the time of a child does not happen under the line of chronos but under the intensity of aion.

'My' daughter can just sit upright. We are on the beach. For what seems forever, she picks up sand in her hands and let it fall through her fingers. I watch in amazement. Her brown curls don't hide her face that is in deep concentration. Her eyes don't look into the world, but are part of it.

Landscapes are not stages, containers, or mere environments for human and nonhuman actors. Landscape is not merely visually akin to a body; it is the skin of the earth. ${ }^{28}$

Barad (2018, p.221) points out that the notion of the linearity of time is salvageable and requires a "radical reworking from within" (p. 220) and cannot or should not be replaced with perhaps a superior, notion of time. Rather than replacing one for the other, which ironically, would be like falling into the trap of the logic of progress, she points out (p.221) 'new' and the 'old' temporalities are already threaded through one another and cannot be separated.

\section{What is needed is an understanding of temporality where the new"}

\footnotetext{
${ }^{27}$ There is a polemic about another word, petteúon, after playing, that would be specifying a specific kind of game that illustrates the way in which aion plays as a child. See Marcovich's comments in Heraclitus 2001.

${ }^{28}$ Barad, 2018, p.238.
} 
and the "old" might coexist, where one does not triumph by replacing and overcoming the other. Quantum superpositions, and relatedly, quantum entanglements, open up possibilities for understanding how the "new" and the "old" - indeed, multiple temporalities - are diffractively threaded through each other, and are inseparable from one another. ${ }^{29}$

Clock time is not universal. There is no single path that counts as human progress, but many, and this counts for children as well as nations.

Land is not property or territory; it is time-being marked by its own wounds and vitality, a layered material geo-neuro-bio-graphy of bones and bodies, ashes and earth, where death and life meet. 30

Some cultures express time spatially (Barad, 2018, p.210), which opens up the idea that time is situated and is neither homogenous, nor empty. For example, Kenyan philosopher John Mbiti shows that for some traditional African societes, time is a bidimensional phenomenon, with only past and present but no future: future is virtually absent because as not yet happened cannot be part of time (Mbiti, 1970, pp.21-23).

Land occupation, as a mode of empire building, has been and continues to be tied to the logics of the void...Newton insisted that the void was a spatial frame of reference within and against which motion takes place...quite literally universal (measuring the full extent of the universe and beyond). ${ }^{31}$

The void is regarded as infinite and continuous as opposed to matter that is finite and discrete. Barad points out that in classical physics the void "literally doesn't matter. It is merely that which frames the absolute" (Barad, 2018, p.230).

... the vacuum is far from empty, for it is filled with all possible indeterminate yearnings of time-being; or in this drum analogy, the

\footnotetext{
${ }^{29}$ Barad, 2018, p.221.

${ }^{30}$ Barad, 2018, p.238.

${ }^{31}$ Barad, 2018, p.230.
} 
vacuum is filled with the indeterminate murmurings of all possible sounds: it is a speaking silence. What stories of creation and annihilation is the void telling? How might we approach the possibility of listening? ${ }^{32}$

What does it mean to listen to child(hood)? What follows when time is not universal and empty, but always spatial? How is time experienced when space is not a neutral container for human movement? Or should we think time beyond space, in a nonspatial logic (like Bergson)?

Inspired by Barad's temporal diffraction (see especially 2018, pp. 229-230), our adoption of travel hopping as method is not like being a historian of childhood, but a diffractive em/bodied re-membering without assuming (self)identity. Re-membering childhood(s) involves philosophical therapy, tracing 'spacetimematter' entanglements with our own marked bodies as researchers - the "bodily activity of re-turning" (Barad, 2018, p.239). Travel hopping is not a travelling through time or space like in some films, but a noticing of the way in which colonising adult/child relationships and particular temporalities have left material-discursive marks on human and nonhuman bodies through iterative school practices. The aim is to produce in a diffractive, not progressive way, new openings and possibilities of be(com)ing-as-part-the-world noticing kinship and re-setting clocks.

...tracing the multiple histories with one's body, putting the self at risk as part of a committed response-ability to those who have died and those not yet born. ${ }^{33}$

...What resides in the void are all those who endure despite layer upon layer of colonial and racialized violence, all those whom the (Hu)Man counts as Other, whether put aside and marked as subhuman, nonhuman, inhuman... ${ }^{34}$.

\footnotetext{
${ }^{32}$ Barad, 2018, p.231.

33 Barad, 2018, p.237.

${ }^{34}$ Barad, 2018, p.241.
} 
The void literally matters and is in/determinate. Neither filled, nor empty, it exists in the virtual realm as possibilities between being and nonbeing and queers the living/dying binary (Barad, 2018, p.231-232). Imaginings have material effects ${ }^{35}$.

\section{...indeterminacy is responsible for the void not being nothing (while not being something), but it may in fact be the source of all that is - a womb that births existence. ${ }^{36}$}

Our relationship with the dead and the not-yet-there, that what is not visible, but still 'there' and 'not there', both spatially and temporally, is an undoing of the Western metaphysics of presence. It is also an undoing of human exceptionalism and the male body as both norm and ideal for what counts as an entity, a self or a person in space and time. ${ }^{37}$ Without bodily boundaries and the im/possibility to differentiate between 'self' and 'other' a different conceptualisation of (self)identity e/merges out of patterns of potentialities and flow with a self as always in flux, 'becoming' rather than 'being' (Battersby,1998, p.55). Such a self is also being and nonbeing at the same time(s) and ruptures the idea of a young and old self as a unity in space and time - an implosion of otherness - difference within, not without.

Barad's reading of chronos through QFT incorporates dimensions of kairos and aion where self is dispersed and diffracted spatially and temporally, and not necessarily chronologically.

\section{Re-turning is a troubling matter, a matter of troubling. ${ }^{38}$}

The relevance of temporal diffraction for childhood and education is that the dis/embodied work of reading personal histories and histories of ideas as texts through

\footnotetext{
${ }^{35}$ Barad's argument here is based on the implications of QFT for understanding the void in classical physics. For the former, an electron is a particle with zero dimensions and without (Cartesian) extension, i.e., it does not take up space, and has no interior, no structure. However, this 'nothingness' is "inseparable from the wild activities of the vacuum", see: Barad, 2018, pp.233-234.

${ }^{36}$ Barad, 2018, p.232.

${ }^{37}$ As argued elsewhere (Murris, 2017), the containment model for bodily boundaries and selves might be more typical of male experiences, which have shaped the Western metaphysical notion of self and self-identity: bodies as containers and selves as ontologically autonomous with properties - a body that is One and not the Other.

${ }^{38}$ Barad, 2018, p. 236.
} 
one another diffractively cuts through misopedy as a colonising logic (thereby also queering the personal/academic binary). Quantum entanglements call into question the very nature of Two: adult, child, but also of One 'Adultchild'.

\section{The renormalized self is a collectivity, not an individual, in an undoing not only of self/other but human/nonhuman. ${ }^{39}$}

Travel hopping as the method adopted troubles the binaries nature/culture and adult/child on which misopedy rests through a diffractive reading of time(s) without erasing the concepts 'child' and 'adult', or the traces of violence the use of these concepts has inflicted upon the subhuman for several centuries. Barad does not suggest we should replace one temporality (e.g. linear) with another (e.g. circular), what is at stake is "the undoing of time, of universal time, of the notion that moments exist one at a time, everywhere the same, and replace one another in succession" (Barad, 2018, p.223). Travel hopping is a deeply personal, academically demanding, non-Cartesian, situated, "embodied material labor" (Barad, 2018, p.223) creating a diffracted time for anyone, anything to experience a childlike education.

Key to being affected by our reasoning is to re-cognise that the internal structure of the childhood of both individuals and society as inferior, is a particular notion of time and space. With the help of a close diffractive reading of one of Barad's recent texts we have troubled a unilinear chronological concept of time. With a re-normalised self as temporal multiplicity ${ }^{40}$, it becomes im/possible to regard adult as also child and...child as also adult. This leads to also having other experiences of time in school, not just chronos, but to include one that is more free, dis/continuous, flexible and diffractive and more aligned with the dis/embodied lived experience of a non-chronological childhood.

\section{Acknowledgements}

\footnotetext{
${ }^{39}$ Barad, 2018, p. 236.

${ }^{40}$ Through a "cutting-together-apart" (Barad, 2014): from-child-within-adult-within-child. Each position in spacetime is a multiplicity - a superposition.
} 
This writing is based on research supported by the National Research Foundation of South Africa [Grant number 98992] and the National Research Foundation of Brasil [Grant number 202447/2017-0]

\section{References}

Author 1, 2016, 2017

Author $1 \&$ other author, in review

Author 2, 2015

Author 2, 2016

Aristotle (2003) Physics. Engl. Transl. R.P. Hardie and R.K. Gaye (Adelaide, The University of Adelaide Press.)

Barad, K. (2003) Posthumanist performativity: Toward an understanding of how matter comes to matter, Signs: Journal of Women in Culture and Society, 28.31, pp. 801-831.

Barad, K. (2007) Meeting the Universe Halfway: Quantum Physics and the Entanglement of Matter and Meaning (Durham, Duke University Press.)

Barad, K. (2012) 'Intra-actions': an interview with Karen Barad by Adam Kleinman, Mousse \#34. June, pp.76-81.

Barad, K. (2014) Diffracting Diffraction: Cutting Together-Apart, Parallax 20.3, pp.168-187.

Barad, K. (2017a) What Flashes Up: Theological-Political-Scientific Fragments. in: C. Keller \& M-J Rubenstein (eds.) Entangled Worlds: Religion, Science, and new Materialisms, pp. 21-89 (New York, Fordham University Press).

Barad, K. (2017b) No Small Matter: Mushroom Clouds, Ecologies of 'Nothingness, and Strange Topologies of Spacetimemattering. in: A. Tsing, H. Swanson, E. Gan \& N. Bubandt (eds.) Arts of Living on a Damaged Planet, pp. G103-G121) (Minneapolis: Universoty of Minnesota Press).

Barad, K. (2018) Troubling Time/s and Ecologies of Nothingness: Re-turning, Remembering, and Facing the Incalculable, in: M.Fritsch, P.Lynes and D.Wood (eds.) Eco-Deconstruction. Derrida and Environmental Philosophy, pp.206-248 (New York, Fordham U Press.) 
Bozalek, V. and Zembylas, M. (2017) Diffraction or reflection? Sketching the contours of two methodologies in educational research, International Journal of Qualitative Studies in Education, 30.2, pp. 111-127.

Crutzen, P.J. and Stoermer, E.F. (2000). The « Antropocene ». Global Change Newsletter, 41, pp.17-18.

Deleuze, G. (1990) Pourparlers. Paris: Les Éditions de Minuit.

Foucault, M. (1995) Discipline and Punish. The birth of the prison (New York, Vintage Books.)

Golden, M. (1990) Child and Childhood in Classical Athens (Baltimore, John Hopkins University Press.)

Honkanen, K. (2007). Aion, Kronos and Kairos: On Judith Butler's Temporality, Journal of Queer Studies in Finland. Available on:

https://journal.fi/sqs/article/view/53674/16796; Accessed 04/08/2018.

Haraway, D. (2016) Staying with the trouble: Making kin in the Chthulucene (Durham and London, Duke University Press.)

Hardt, M. and Negri, A. (2001). Imperium (Harvard, Harvard University Press.)

Heraclitus (2001) Maior Edition by Miroslav Marcovich (Sankt Augustin, Academia Verlag.)

Kohan, W. (2015) The inventive schoolmaster. Rotterdam: Sense.

Liddell, H. and Scott, R. (1966) A Greek English Lexicon (Oxford, Clarendon Press.)

Masschelein, J. and Simons, M. (2014) In defense of school: A public issue.

Transl. Jack McMartin (Leuven, E-ducation, Culture \& Society Publishers.)

Massumi, B. (2015) The Politics of Affect (Cambridge: Polity Press.)

Mazzei, L.A. (2014) Beyond an Easy Sense: A Diffractive Analysis, Qualitative Inquiry, 20.6, pp. 742-746.

Mbiti, John S. (1970) African Religions and Philosophy (Nova Iorque: Anchor Books.)

Murris, K. (2016). The Posthuman Child: Educational Transformation through Philosophy with Picturebooks. London: Routledge. Routledge Contesting Early Childhood Series.

Murris, K; Babamia (2018) 
Murris, K. and Bozaleck, V. (2019). Diffraction and response-able reading of texts: the relational ontologies of Barad and Deleuze. International Journal of Qualitative Studies in Education https://doi.org/10.1080/09518398.2019.1609122

Pacini-Ketchabaw, V. (2012) Acting with the Clock: clocking practices in early childhood, Contemporary Issues in Early Childhood, 13.2, pp.154-160.

Plato (1989) The Collected Dialogues. Edited by Edith Hamilton and Hungtington Cairns (Princeton, Princeton University Press, Bollingen Series LXXII.)

Rancière, J. (1988) École, production, égalité. In: L'école de la démocratie (Edilig: Fondation Diderot.)

Rodríguez, S. (2001) Obra Completa (Caracas, Presidencia de la República.)

Rollo, T. (2018) Feral children: settler colonialism, progress, and the figure of the child, Settler Colonial Studies, 8.1, pp. 60-79.

Tsing, A.L. (2015). The Mushroom at the End of the World.: on the possibility of life in capitalist ruins. (Princeton: Princeton University Press.)

Wiercinski, A. (2017) Hermeneutic Education to Understanding: Self-Education and the Willingness to Risk Failure, in: P. Fairfield (ed.) Education, Dialogue and Hermeneutics, pp. 107-123 (London, Bloomsbury).

Shahjahan, R.A. (2018) Re/conceptualizing time in higher education, Discourse: Studies in the Cultural Politics of Education, 1-12.

Snaza, N. (2015) Toward a Genealogy of Educational Humanism. in: N. Snaza \& J.A. Weaver. Posthumanism and Educational Research. (New York: Routledge) pp.17-30.

Swanson, H., Tsing, A., Bubandt, N., and Gan, E. (2017) Introduction: Bodies Tumbled into Bodies. In: A. Tsing, H. Swanson, E. Gan \& N. Bubandt (eds.) Arts of Living on a Damaged Planet, pp. M1-M15 (Minneapolis: Universoty of Minnesota Press). 


\section{Troubling troubled school time}

\section{Corresponding author: Walter Omar Kohan}

\section{Contact details:}

Professor Walter Kohan (PhD)

Universidade do Estdo do Rio de Janeiro - UERJ

R. São Francisco Xavier 524

Sala 12037 F PROPEd

Rio de Janeiro, RJ, Brazil

Cel + 5521-981705758

Emailwokohan@gmail.com

Co-author:

Professor Karin Murris (PhD)

School of Education

University of Cape Town

Cape Town

South Africa

Tel 0216502835

Cell 0795762456

Email Karin.murris@uct.ac.za 